Artigo Original

Original Study

\title{
Política nacional para a detecção de talentos esportivos: uma proposta baseada em experiências de sucesso
}

\section{Sports Talents Detection National Policy: A Proposal Based on Successful Experiences}

Luciano Vieira $^{\S 1,2}$ MS; Alfredo Gomes Faria Junior ${ }^{2}$ PhD; Danielli Braga de Mello ${ }^{3}$ PhD; Roberto Ferreira dos Santos ${ }^{2}$ PhD; Lilian C X Martins² PhD; José Maurício Capinussú (In Memoriam) PhD

Recebido em: 29 de agosto de 2018. Aceito em: 20 de setembro de 2018

Publicado online em: 09 de outubro de 2018.

\section{Resumo}

Introdução: 0 Governo brasileiro tem a intenção de estar entre os dez primeiros países no ranking de medalhas dos Jogos Olímpicos. Entretanto, o Brasil não tem atingido esse objetivo. Surgem questões a respeito dos motivos desse insucesso. Nesse sentido, é importante analisar como se apresenta a política nacional de deteç̧ão de talentos esportivos face a teoria e a prática.

Objetivo: Analisar criticamente a situação atual da política nacional voltada para a descoberta de talentos esportivos e examinar as práticas de países com políticas que têm obtido êxito no esporte para desenvolver uma proposta para o Brasil.

Métodos: Aplicação de um questionário, desenvolvido para o estudo, aos dirigentes das equipes dos Jogos Olímpicos Rio 2016, e análise documentária.

Resultados: A política nacional brasileira voltada para a descoberta de talentos esportivos, por meio dos programas do Ministério do Esporte, não tem se mostrado eficiente em relação à intenção de governo de estar entre os dez primeiros no ranking de medalhas olímpicas. Observa-se que a política brasileira para o esporte tem propostas que interligam o esporte à educação, porém, como na prática os programas não foram sequer implementados ou não foram eficientes, não se obtém resultados de sucesso.

Conclusão: Observando as deficiências da política brasileira em relação à Detecção de Talento Esportivo, juntamente com as políticas dos países de sucesso no esporte, apresentou-se uma proposta de

\section{Pontos-Chave Destaque}

- A política nacional brasileira

para a descoberta de talentos

esportivos (PNBDTE) não tem se

mostrado eficiente.

- O esporte deve estar

integrado à educação. A

PNBDTE contempla este pressuposto. Há uma distância entre a teoria (a PNBDTE) e a prática (efetividade dos programas), que inviabiliza a obtenção do sucesso em relação aos objetivos propostos.

- Foi elaborada uma proposta com o objetivo de diminuir essa distância.

Política Nacional para a Detecção do Talento Esportivo.

Palavras-chave: talento esportivo; detecção de talento esportivo; política do esporte.

\section{Abstract}

Introduction: The Brazilian Government intends the country to be among the top ten countries in the Olympic Games medal ranking. However, Brazil has not achieved this goal. Questions on the reasons for this failure arise.

\footnotetext{
$\S$ Autor correspondente: Luciano Vieira - e-mail: lucianovieira1973@gmail.com Afiliações: ${ }^{1}$ Universidade Salgado de Oliveira (UNIVERSO); ${ }^{2}$ Instituto de Pesquisa da Capacitação física do Exército (IPCFEx); ${ }^{3}$ Escola de Educação Física do Exército (ESEFEX).
} 
Therefore, it is important to analyze how the national policy for sports detection of talents is presented in relation to theory and practice.

Objective: To critically analyze the current situation of the national politics focused on the discovery of sports talent and to examine the practices of countries with policies that have been successful in the sport to develop a proposal for Brazil.

Methods: Application of a questionnaire, developed for the study, to the leaders of the teams of the Olympic Games Rio 2016, and documentary analysis.

Results: The Brazilian national policy focused on the discovery of sports talent, through the programs of the Ministry of Sports, has not been efficient in relation to the government's intention to be among the top ten in the Olympic medal ranking. It is observed that the Brazilian policy for sport has proposals that link sport to education, but as in practice the programs have not even been implemented or were not efficient, they do not obtain successful results.

Conclusion: Noting the deficiencies of the Brazilian policy regarding the Detection of Sports Talent, together with the policies of the countries of success in the sport, a proposal of National Policy for the Detection of Sports Talent was presented.

\author{
Keypoints \\ - The Brazilian national policy \\ for the discovery of sports \\ talent (BNPDST) has not been \\ efficient. \\ - Sport must be integrated with \\ education. BNPDST \\ contemplates this assumption. \\ There is a distance between \\ theory (the BNPDST) and \\ practice (effectiveness of \\ programs), which leads to the \\ impossibilitye to reach the \\ objectives. \\ - A proposal was drawn up to \\ reduce this distance.
}

Keywords: sports talent; sports talent detection; sport politics.

\section{Política nacional para a detecção de talentos esportivos: uma proposta baseada em experiências de sucesso}

\section{Introdução}

Em tempos em que a política tem se mostrado recorrente em aparecer em todas as mídias brasileiras, infelizmente de maneira negativa, esse estudo discorrerá sobre a política nacional para a detecção de talentos esportivos.

O tema pesquisas comparativas das políticas para o esporte de alto rendimento é um tema atual da Ciência do Esporte, tanto no contexto nacional quanto no internacional(1). No esporte de alto rendimento observa-se a crescente procura por novos talentos. Essa procura é fomentada pelos clubes, empresas e empresários. Como consequência, a seleção dos atletas está sendo antecipada a cada dia, ou até mesmo prematura(2). A representatividade de uma nação no esporte inicia-se na descoberta de seus talentos esportivos(2). Uma política efetiva para a descoberta de talentos possibilita que os mesmos, além de descobertos em idade ideal, possam se desenvolver e representar satisfatoriamente a sua nação(3).

Os resultados obtidos pelos atletas não dependem somente de sua detecção em época ideal, existem inúmeros fatores intervenientes que contribuem ou dificultam esse caminho. Em um nível macro de análise, segundo Bosscher et al.(4), o sucesso internacional no esporte, é influenciado por fatores como: população, bem-estar, variação climática e sistema político. Segundo os autores, uma população numerosa favorece a busca de atletas, como é o caso da China.

A literatura mostra que mais de $50 \%$ do sucesso esportivo no cenário internacional pode ser explicado por três aspectos: população, riqueza (expressa como produto interno bruto per capita) e o antigo comunismo, como um particular sistema político(4). Nessa perspectiva, observou-se que a população brasileira era de 204.576.636 de habitantes, no censo de 2015, distribuídos em um território de 8,5 milhões de $\mathrm{km} 2$, de 
clima tropical(5). Essas condições, ambiental e populacional, fazem do Brasil um país supostamente favorável à prática desportiva.

Bosscher et al.(4) defendem que uma das maneiras de se medir a produção de atletas por um país é contando o número de medalhas conquistadas durante os Jogos Olímpicos. Outra maneira é dividindo o número de medalhas pela população do país. Observa-se que o Brasil nunca teve uma participação significativa em número de medalhas em Jogos Olímpicos se comparado aos países europeus, embora tenha uma grande população e uma imensa extensão territorial, que sugere ser favorável ao desenvolvimento do esporte.

Nos últimos Jogos Olímpicos, realizados em casa, o Brasil obteve apenas sete medalhas de ouro, seis de prata e seis de bronze(6). Esse montante the conferiu a $13^{\text {a }}$ colocação do ranking de medalhas, dentre os 207 países e territórios participantes. Certamente, esse avanço no ranking do quadro de medalhas se deve ao planejamento, organização e coordenação do esporte.

Apesar dos últimos resultados medianos, se comparados aos três melhores países do mundo, no ranking de medalhas (Estados Unidos, Reino Unido e China)(6), o Brasil encontra-se, ainda, em fase inicial de estruturação da política voltada para o esporte. De acordo com o Decreto 7984/2013 da Presidência da República, o Plano Nacional do Desporto pretendeu organizar a atuação governamental e estabelecer metas e objetivos, construindo uma visão de longo prazo para o esporte(7). O que ainda não pode ser efetivamente observado na prática.

As condições favoráveis numéricas populacionais, territoriais e climáticas, já citadas acima, sugerem que o Brasil possui um enorme potencial para almejar estar entre os dez primeiros colocados no ranking de medalhas dos Jogos Olímpicos. As vontades política, por meio do plano Brasil Medalhas do Ministério do Esporte de 2012, e social caminham nesta direção, porém, por que esse objetivo não se realiza? Seria pela falta de uma política eficiente de descoberta de talentos esportivos ou haveria outros fatores intervenientes?

A detecção de valores esportivos aguça o interesse de diversas empresas que mergulham nessa procura a fim de buscar atletas para representar a sua marca e gerar lucros de audiência. Nesse contexto, um fator que falta às empresas privadas é um mecanismo de abrangência nacional a fim de abarcar toda a população brasileira na idade desejada para sua pesquisa de detecção de talentos. Esse fator, ou poder de mobilização nacional, cabe apenas às entidades governamentais e o governo brasileiro possui diversos programas esportivos que visam a detecção e promoção do atleta. Da análise das políticas nacionais voltadas para a Detecção de Talento Esportivo (DTE) observa-se a sua efetividade ou não, em relação ao objetivo a que se propõe.

Este estudo teve como objetivo realizar uma análise crítica dos resultados da pesquisa da situação atual da política nacional voltada para a DTE; e apresentar uma proposta para essa política, baseada em experiências de sucesso.

\section{Métodos}

\section{Desenho de estudo e amostra}

Foi realizada uma pesquisa qualiquantitativa, transversal e descritiva, com delimitação na política brasileira de $\operatorname{DTE}(8)$. Para tanto, procedeu-se a uma análise documental(10) e foi elaborado um questionário para ser aplicado a integrantes do âmbito esportivo olímpico do Brasil. A população elegível para participar selecionada para a pesquisa foram os dirigentes (técnicos ou chefes de equipe) dos Jogos Olímpicos Rio $2016(\mathrm{~N}=42)$.

\section{Aspectos éticos}

A pesquisa foi enviada ao Comitê de Ética em Pesquisa da Universidade Salgado de Oliveira (UNIVERSO) e foi aprovada sob o número registro da plataforma Brasil do Certificado de Apresentação para Apreciação Ética (CAAE) 69609517.0.0000.5289. Foram garantidos o anonimato e o sigilo das informações, sendo revelada somente a função do dirigente esportivo e a modalidade em questão. A utilização dos resultados foi exclusiva para fins científicos.

\section{Análise documental}

A análise documental foi proposta para identificar os processos que compõem a política nacional de identificação de talentos 
desenvolvidos nos esportes estudados. Buscou-se, na internet, em sites oficiais do Ministério do Esporte e do Comitê Olímpico do Brasil (COB), os programas de governo referentes a políticas para o esporte e, desta forma, foram identificados os programas políticos voltados para a DTE existentes no país.

A fim de comparar a política nacional para o esporte com políticas internacionais de sucesso, utilizou-se como base o livro Successful Elite Sport Policies - an International Comparison of the Sports Policy Factors Leading to International Sporting Success in 15 Nations (Políticas bemsucedidas do esporte de elite - uma comparação internacional dos fatores da política esportiva que levam ao sucesso esportivo internacional em 15 nações)(4).

Os processos componentes dos programas identificados foram categorizados e codificados da seguinte maneira: a letra " $A$ " designou programas do governo de DTE; a letra "B" designou programas privados de DTE; e a letra " $C$ " designou o grupo de atletas não detectados por programas de DTE.

\section{Instrumento de pesquisa}

Foi desenvolvido um questionário específico para a presente investigação. A fim de imprimir confiabilidade ao conteúdo e à forma quanto a pertinência, clareza e presença de viés nas questões propostas, o questionário foi submetido à apreciação de três especialistas na conhecedores tanto de políticas públicas e privadas em gestão esportiva, quanto conhecedores deste método de pesquisa. Todos julgaram o instrumento de pesquisa pertinente, claro e direcionado, fazendo observações quanto à forma das perguntas para melhorar a compreensão. A partir das observações dos especialistas, o instrumento foi revisado e só então, aplicado para a realização da pesquisa.

\section{Procedimentos de coleta de dados}

A coleta de dados dividiu-se em dois momentos distintos: o processo de aplicação do questionário e $\mathrm{o}$ processo de análise documental.

Para a aplicação do questionário, contatouse o dirigente de cursos do COB. Na aquiescência do COB. Inicialmente, o pesquisador apresentou uma explanação sucinta, quanto ao objetivo e métodos da pesquisa, o tempo destinado para preenchimento do questionário aos gestores das equipes brasileiras das modalidades olímpicas.

No aceite em preencher o questionário, foi agendada uma data de melhor conveniência para o gestor responsável de cada modalidade. $\mathrm{O}$ questionário foi aplicado de forma individual, em ambiente privado e conduzido apenas após a assinatura do termo de consentimento livre e esclarecido.

\section{Análises de dados}

Para a análise dos dados gerados pelos questionários foi utilizada a decomposição temática(11) das respostas geradas a partir das transcrições das mesmas por temas. Os autores, afirmaram que "a decomposição temática é uma leitura atenta que tenta separar o texto em temas ou histórias coerentes. Esta abordagem baseia-se na ideia de que o discurso não expressa ou relata significados simplesmente, antes, os significados são construidos através do discurso"(11). Desta decomposição temática buscou-se separar os temas de acordo com as questões a investigar, utilizando-se de códigos alfabéticos.

Devido à natureza exploratória e descritiva desta pesquisa, as informações foram abordadas de uma forma mais descritiva que interpretativa. As informações da análise documentária, como do questionário aplicado, passaram pelo mesmo processo de identificação temática. Os resultados de ambas as fontes de informação (questionário e documentos) foram apresentados juntos na discussão de resultados.

A parte estatística, extraída do questionário, desenvolveu-se através da estatística descritiva com a porcentagem simples a fim de verificarmos o percentual de chefes de equipe que conheciam algum programa de DTE como também para se levantar o percentual de atletas participantes dos Jogos Olímpicos que surgiram através de programas de DTE.

\section{Resultados}

Dos 42 chefes de equipe para os Jogos Olímpicos Rio 2016, 21 participaram da pesquisa. Como a perda amostral foi maior que 
$20 \%$, calculou-se a margem de erro do estudo, com nível de confiança a 95\%, para uma probabilidade de $5 \%$ de que houvessem resultados divergentes do esperado, a margem de erro foi de $6,67 \%$. Os resultados referem-se à aplicação do questionário especificamente desenvolvido para este estudo e das informações documentais da experiência de sucesso exibida em outros países.

\section{Percepção dos chefes de equipes/técnicos quanto à detecção de talentos esportivos (DTE)}

Quanto à A Tabela 1 apresenta as características da amostra e as frequências de existência e tipo de programas de DTE, quantidade de atletas da modalidade e quantitativo de atletas originários de programas de DTE. Dos 21 participantes do estudo, 12 chefes de equipe/técnicos $(57,14 \%)$, para os Jogos Olímpicos Rio 2016, não conheciam nenhum programa de DTE. Dos nove chefes de equipe/técnicos que conheciam algum programa, seis $(28,57 \%)$ tiveram atletas advindos dos mesmos. Do total de 410 atletas das 21 modalidades que fizeram parte da pesquisa, $30(7,32 \%)$ eram oriundos de algum programa de DTE distribuídos em apenas seis modalidades: atletismo, remo, basquete feminino, canoagem, saltos ornamentais e handebol feminino.

Tabela 1 - Modalidades olímpicas e os programas de detecção de talentos esportivos (DTE) descrição e quantitativo informados pela amostra $(n=21)$

\begin{tabular}{|c|c|c|c|c|c|}
\hline $\begin{array}{l}\text { Esporte } \\
\text { Olímpico }\end{array}$ & $\begin{array}{l}\text { O chefe da equipe } \\
\text { conhecia algum } \\
\text { programa de DTE? }\end{array}$ & $\begin{array}{l}\text { Público ou } \\
\text { Privado? }\end{array}$ & $\begin{array}{l}\text { Onde ocorre o programa de } \\
\text { DTE? }\end{array}$ & $\begin{array}{c}\text { Total } \\
\text { de } \\
\text { atletas }\end{array}$ & $\begin{array}{c}\text { Atletas } \\
\text { DTE }\end{array}$ \\
\hline Vôlei de praia & Não & - & - & 08 & - \\
\hline Golfe & Não & - & - & 03 & - \\
\hline Atletismo & Sim & $?$ & Não soube dizer. & 66 & 08 \\
\hline $\begin{array}{l}\text { Nado } \\
\text { sincronizado }\end{array}$ & Não & - & - & 09 & - \\
\hline Rúgbi & Não & - & - & 120 & - \\
\hline Tiro esportivo & Não & - & - & 05 & - \\
\hline $\begin{array}{l}\text { Ginástica } \\
\text { Artística }\end{array}$ & Sim & Público & $\begin{array}{l}\text { Universidade Federal do Rio } \\
\text { Grande do Sul (UFRGS), } \\
\text { Porto Alegre -RS }\end{array}$ & 12 & - \\
\hline Remo & Sim & Privado & $\begin{array}{l}\text { Porto Alegre-RS } \\
\text { São Francisco do Sul-SC }\end{array}$ & 24 & 08 \\
\hline Badminton & Sim & Privado & Rio de Janeiro-RJ & 16 & - \\
\hline $\begin{array}{l}\text { Basquete } \\
\text { feminino }\end{array}$ & Sim & Privado & Americana-SP & 12 & 02 \\
\hline Boxe & Não & - & - & 09 & - \\
\hline Tênis de mesa & Sim & Privado & Todas as regiões & 06 & - \\
\hline Tiro ao prato & Não & - & - & 04 & - \\
\hline $\begin{array}{l}\text { Pentatlo } \\
\text { moderno }\end{array}$ & Não & - & - & 20 & - \\
\hline Canoagem & Sim & Público & $\begin{array}{c}\text { Prefeitura Municipal, Caxias } \\
\text { do Sul }\end{array}$ & 05 & 02 \\
\hline Hipismo CCE & Não & - & - & 05 & - \\
\hline $\begin{array}{l}\text { Saltos } \\
\text { ornamentais }\end{array}$ & Sim & $\begin{array}{l}\text { Público e } \\
\text { Privado }\end{array}$ & $\begin{array}{c}\text { Universidade Federal de } \\
\text { Brasília (UnB) e privado, } \\
\text { Brasília-DF }\end{array}$ & 09 & 02 \\
\hline Polo aquático & Não & - & - & 13 & - \\
\hline Esgrima & Não & - & - & 16 & - \\
\hline Natação & Não & - & - & 33 & - \\
\hline $\begin{array}{l}\text { Handebol } \\
\text { feminino }\end{array}$ & Sim & Público & $\begin{array}{l}\text { Jogos Escolares, Prefeitura } \\
\text { Municipal, Jundiaí-SP }\end{array}$ & 15 & 08 \\
\hline TOTAL & $\operatorname{Sim}=9$ Não $=12$ & & & 410 & 30 \\
\hline
\end{tabular}


Das políticas nacionais voltadas para a DTE

A Tabela 1 apresenta os resultados do questionário aplicado nas modalidades olímpicas brasileiras em relação a programas de DTE. Dos 17 programas de governo identificados apenas dez relacionam-se com a DTE. Dos 410 atletas dessas modalidades apenas $30(7,32 \%)$ originaram-se de algum programa de DTE.
A Tabela 2 apresenta um resumo dos resultados quanto aos programas nacionais de governo referentes às políticas para detecção de talento esportivo (DTE). Dentre os dez programas elencados como possíveis favorecedores da detecção do talento esportivo no Brasil, apenas dois se voltam a esse papel, e apresentaram importantes limitações.

Tabela 2 - Programas nacionais de governo referentes às políticas para detecção de talento esportivo (DTE)

\begin{tabular}{ll}
\hline Programa & Objetivos \\
\hline \hline Brasil & $\begin{array}{l}\text { Formar novas gerações de atletas e estruturar centros } \\
\text { Me treinamentos que atendessem as equipes principais } \\
\text { desde o alto rendimento ate as categorias de base. }\end{array}$
\end{tabular}

Rede Nacional de Treinamento(13)

Centro de Iniciação ao Esporte(14)

Centros Olímpicos de Treinamento(15)

Segundo Tempo(16)

Atleta na

Escola(17)

Esporte na

Escola(18)

Futebol

Feminino(19)

Sistema Nacional do Esporte(20)

Legado Esportivo(21)
Formar uma Rede Nacional de Treinamento, interligando as diversas instalações esportivas existentes ou em construção no país.

Ampliar a oferta de infraestrutura de equipamento público esportivo qualificado, dentro do Programa de Aceleração do Crescimento versão 2 (PAC2).

Utilizar o Legado dos Jogos Olímpicos Rio 2016.

Democratizar o acesso à prática e à cultura do Esporte, de forma a promover o desenvolvimento integral de crianças, adolescentes e jovens, como fator de formação da cidadania e melhoria da qualidade de vida, prioritariamente em áreas de vulnerabilidade social.

Fomentar a prática esportiva escolar, em todas as suas etapas: escolar, municipal, estadual e nacional.

Integrar o esporte à educação, juntando os programas Segundo Tempo e Mais Educação.

Fortalecer a formação de base e investir na realização de campeonatos.

Promover e fomentar políticas esportivas para toda a população brasileira.

Definir a infraestrutura de treinamento, como as instalações construídas para os Jogos Olímpicos e as previstas para ser construídas, como os Centros de Iniciação ao Esporte.

\section{Principais problemas}

Não foram construídos os centros de treinamentos para atender os atletas.

Não foram construídos os centros de treinamento e as arenas dos JO não estão sendo utilizadas para DTE.

Não existiu pois não foi realizado o PAC2.

As arenas dos JO Rio2016 não estão sendo utilizadas para DTE.

O foco do programa é no esporte como integração social, saúde e lazer, não atendendo a DTE.

Falta incentivo às escolas para participar do programa.

Foco no desenvolvimento social, saúde e lazer através do esporte, e não busca a detecção de talentos esportivos.

Atende somente uma modalidade esportiva.

Não foi colocado em prática.

Foi construído apenas o necessário à realização dos JO Rio2016 e mesmo estes não estão sendo utilizados para DTE. 


\section{Discussão}

De acordo com os resultados do questionário (Tabela 1), a taxa de atletas oriundos de programas de DTE é muitíssimo baixa: menor do que dez por cento (7,32\%). Estes resultados expressam o insucesso das propostas de existentes no país, cuja discussão apresenta-se a seguir.

\section{Brasil Medalhas}

O plano de governo Brasil Medalhas visava colocar o Brasil entre os 10 primeiros países dos Jogos Olímpicos e entre os cinco primeiros dos Jogos verba de um bilhão de reais desde o início da preparação para os jogos Rio 2016(12). Desse montante, a maioria foi gasto com apoio às seleções de atletas, contratação de técnicos, equipamentos, materiais, viagens para treinamento e competições. A menor parte, cerca de 450 milhões de reais, foi destinada para construção, reforma e equipagem de centros de treinamento de várias modalidades e complexos multiesportivos.

Da verba destinada à construção, reforma e equipagem dos Centros de Treinamento foram construídas somente as arenas destinadas aos Jogos Rio 2016, na Barra e Deodoro. E mesmo estas, não estão sendo utilizadas a fim de preparar as seleções nacionais e formar novos talentos, que eram objetivos desse programa, exceto o Centro Militar de Tiro Esportivo Tenente Coronel Guilherme Paraense e o Parque Equestre General Eloy Menezes que se encontram em utilização para treinamento e campeonatos nacionais das modalidades.

\section{Rede Nacional de Treinamento}

O programa, Rede Nacional de Treinamento foi criado em 2011 e tinha por objetivo interligar a infraestrutura esportiva do país e construir novos complexos esportivos para atender às categorias de base até o alto rendimento(13). Repetindo o descrito no programa Brasil Medalhas, não foram construídas novas instalações esportivas, apenas o Complexo Esportivo da Barra e o de Deodoro. Este projeto não saiu do papel em relação às instalações destinadas a detecção de talentos esportivos.

\section{Centro de Iniciação ao Esporte}

O programa Centro de Iniciação ao Esporte visava criar espaços para o desenvolvimento da base do esporte de alto rendimento(14). Portanto, o objetivo era ampliar a oferta de infraestrutura de equipamento público esportivo qualificado, incentivando a iniciação esportiva em territórios de alta vulnerabilidade social das grandes cidades brasileiras. O projeto integra, num só espaço físico, atividades e a prática de esportes voltados ao alto rendimento, estimulando a formação de atletas entre crianças e adolescentes. Exatamente o foco do artigo em questão, o que certamente seria muito positivo para a detecção de talentos esportivos no Brasil. Porém, segundo o Ministério do Esporte(14), o programa estava atrelado a segunda etapa do Programa de Aceleração do Crescimento (PAC2), e por falta de verba não foi executado.

\section{Centros Olímpicos de Treinamento}

O programa Centros Olímpicos de Treinamento propunha a utilização das arenas da Barra da Tijuca e de Deodoro para a detecção, seleção e promoção do talento esportivo visando o alto rendimento.

Compilando as informações do Ministério do Esporte verifica-se a falta de fomento para a utilização dos Centros Olímpicos, que com encargos financeiros pesados para essa utilização, acabam não sendo utilizados ou são utilizados para outros fins que não o esportivo. Desta forma, seu ideal não vem ocorrendo de maneira satisfatória para a seleção de talentos como para o treinamento das equipes nacionais, sendo apenas utilizadas para outros fins visando sua sustentabilidade, ou sobrevivência.

\section{Segundo Tempo}

O objetivo do programa Segundo Tempo é democratizar o acesso à prática e à cultura do esporte. Com esse objetivo, observa-se que o foco do programa reside no esporte como integração social, saúde e lazer, ficando a descoberta de algum atleta de talento, deixada por conta do acaso, pois, este não é o foco do programa.

\section{Atleta na Escola}

O programa Atleta na Escola, de fato, fomenta a prática esportiva escolar, em todas as suas esferas: municipal, estadual e nacional. Desta forma, a detecção de novos talentos esportivos ou atletas do alto rendimento surgem em meio às competições, caso essas 
competições abarquem todos os esportes olímpicos.

As limitações do programa são: a não obrigatoriedade de participação de todas as escolas, ficando a cargo das mesmas a inscrição nas competições, a falta de incentivo para o atleta, como bolsas de estudo, equipamentos para motivar a participação de mais jovens e a inclusão de todos os esportes olímpicos nas competições escolares. Outro ponto negativo, é que os talentos detectados pelo programa Atleta na Escola devem ser acolhidos pelos Centros de Iniciação Esportiva, os quais ainda não foram construídos.

\section{Esporte na Escola}

O programa Esporte na Escola faz a integração do Programa Segundo Tempo e do Programa Mais Educação. O programa tem como objetivo o desenvolvimento social, saúde e lazer através do esporte, e não busca a detecção de talentos esportivos.

\section{Futebol Feminino}

O programa futebol feminino estruturou o a modalidade no Brasil, criou competições, apoiou a base desse esporte e incentivou as competições escolares. É um programa que deu certo, fortaleceu o futebol feminino e fez despontar novos atletas para o Brasil. A única limitação é atender apenas um esporte, e apenas o seguimento feminino.

\section{Sistema Nacional do Esporte}

O Sistema Nacional do Esporte teve como objetivo consolidar o esporte como uma política pública estruturante e alçar o Brasil a uma condição de potência esportiva sustentável. O programa tinha bases sólidas para um bom desempenho na detecção de talentos esportivos, pois definia os serviços a serem ofertados e os responsáveis pela execução das diretrizes, sejam no âmbito das entidades públicas (União, Estados e Municípios), sejam em colaboração com as entidades privadas. $\mathrm{O}$ óbice do programa foi não ter sido colocado em prática.

\section{Legado Esportivo}

O programa Legado Esportivo se confunde com a Rede Nacional de Treinamento, com os Centros Olímpicos de Treinamento, com os Centros de Iniciação ao Esporte (CIE) e com o
Atleta na Escola, pois, define a infraestrutura de treinamento como as instalações construídas para os Jogos Olímpicos, mas não prevê outros recursos administrativos para que os objetivos fossem alcançados. Sendo assim, o pouco legado que restou não está atingindo o objetivo proposto de fomentar o esporte e proporcionar a DTE.

\section{Síntese de efetividade dos programas}

Observou-se que dos 17 programas de governo existentes apenas dez se relacionam com a DTE. E dos dez programas de governo relacionados a DTE, apenas dois se voltam a esse papel, porém, exibindo importantes limitações que levam a poucos resultados tanto em sucesso no cenário esportivo internacional quanto na contribuição que o esporte pode proporcionar no desenvolvimento educacional de crianças e adolescentes. Estes resultados apresentam-se como de extrema relevância, pois, o pensamento filosófico do movimento olímpico abrange tanto o sucesso no desempenho esportivo quanto efetividade em ações que contribuam para a saúde da população e da formação educacional de jovens e crianças. Tais ideias compõem o conceito de olimpiíssimo. Segundo Tubinho(22), o Olimpiíssimo é a própria filosofia do esporte, que exalta as qualidades do corpo, a vontade e o espírito humanos, associando a prática do esporte à educação e à cultura. Objetiva, também, promover valores que contribuem para o estilo de vida das pessoas, por meio da alegria do esforço físico, do valor educativo presente no bom exemplo e pelo respeito aos princípios éticos universais (22). Nesse sentido, a ausência de efetividade dos programas nacionais deixa de utilizar a prática esportiva como importante estratégia de desenvolvimento da sociedade e de promoção da saúde.

\section{Uma proposta de política nacional para a DTE baseada em experiências de sucesso}

A presente proposta foi elaborada considerando que países que têm sucesso, no âmbito do alto rendimento, apresentam o desenvolvimento do esporte interligado com a educação(4). Além disso, a DTE é fundamental para que o Brasil eleve seu nível de desempenho esportivo, em relação ao número de medalhas olímpicas. 
Observou-se que não existe consenso quanto à necessidade de centralização ou de grande intervenção do governo nas políticas esportivas de elite. Entretanto, no Brasil, há um entendimento de que somente o governo tem o poder de obediência e recrutamento de toda a população através de leis, normas e regulamentos que favorecem o esporte.

Outro fator a ser considerado trata-se da importância do envolvimento das partes interessadas (stakeholders) no desenvolvimento da política esportiva de elite(4).

Nesse contexto, e alinhada ao cenário brasileiro identificado pelo presente estudo, foi elaborada uma proposta visando a efetividade de programas e políticas para o esporte.

O primeiro passo a ser realizado pelo Ministério do Esporte - responsável por desenvolver a Política Nacional do Esporte(23), seria a criação de uma Secretaria Nacional de Detecção de Talentos. Essa ação deve ser coordenada pelo Departamento de Incentivo e Fomento ao Esporte, com o apoio da Assessoria Especial de Projetos. Dessa forma a Secretaria Nacional de Esporte de Alto Rendimento ficaria voltada diretamente para a promoção do Talento Esportivo enquanto a Secretaria Nacional de Detecção de Talentos se voltaria para a detecção do talento como descreve o seu nome.

$\mathrm{O}$ segundo passo rumo à $10^{\mathrm{a}}$ colocação no ranking de medalhas dos Jogos Olímpicos, seria a estruturação de uma Secretaria Nacional de Detecção de Talentos, atribuindo objetivos e responsabilidades. Essa definição de responsabilidades é importante para estruturar de maneira coesa o sistema nacional do esporte. Isto está definido no programa de governo Sistema Nacional do Esporte, faltando apenas vontade política para colocá-lo em prática.

Após estruturar a Secretaria Nacional de DTE, o passo seguinte seria determinar aos estados que criem suas Secretarias Estaduais de Detecção de Talentos, a fim de darmos uma capilarização nacional à DTE. Essas Secretarias que deverão identificar as necessidades das escolas para a prática esportiva e, então, monitorar o incentivo ao esporte. Além disso, devem ser oferecidas bolsas escolares aos atletas, disponibilizar profissionais capacitados, promover jogos escolares municipais, estaduais e federais estruturados e desenvolvendo, assim, uma cultura do esporte na escola seguindo o exemplo do modelo norte americano.

Com essas ações, o Brasil define os responsáveis pela execução de cada tarefa na Detecção do Talento Esportivo, sejam no âmbito das entidades públicas (União, Estados e Municípios), sejam em colaboração com as entidades privadas.

Os países de sucesso no esporte de alto rendimento, possuem políticas que fazem o esporte caminhar lado a lado com a Educação(4). Portanto, o Brasil deve fortalecer o esporte nas escolas incentivando e até mesmo obrigando que as mesmas (públicas e privadas) participem dos jogos escolares (municipais, estaduais e federais) e ofereçam $15 \%$ de bolsas integrais aos jovens atletas, através de regulação por leis específicas. Isso fomentaria o esporte e teria como consequência a detecção de valores esportivos.

Outro passo seria a criação de Centros de Iniciação ao Esporte, em todos os Estados, que atendam a todas as modalidades olímpicas. Esses centros devem integrados às escolas, para favorecer o binômio esporte/educação. Desta forma, em todos os Estados da teríamos, ao menos, uma instalação voltada para cada uma das 42 modalidades olímpicas.

For fim, o último passo seria o fortalecimento do esporte Universitário, por meio da realização de competições Estaduais e Federais, obrigando todas as Universidades a fornecerem $15 \%$ de bolsas integrais aos atletas, sendo essa ação regulada por lei específica.

Tal proposta visa que se inicie, no Brasil, uma cultura do esporte desenvolvida a partir de se fazer com que a educação caminhe junto com o esporte, de forma semelhante ao que se faz nos Estados Unidos da América. A partir dessa cultura, o Brasil crescerá tanto no esporte como também na educação e, adicionalmente, os ex-atletas brasileiros podem ser empregados na preparação de novos atletas de alto rendimento.

Resumo das ações apresentadas na proposta

- Criar a Secretaria Nacional de Detecção de Talentos Esportivos (SNTE);

- Estruturar a SNTE; 
- Atribuir objetivos e responsabilidades a SNTE;

- Criar as Secretarias Estaduais de Detecção de Talentos Esportivos;

- Incentivar a participação esportiva na escola (pública e particular);

- Fortalecer os Jogos Escolares (Municipais, Estaduais e Federais);

- Elaborar e publicar Lei regulando a obrigatoriedade de participação nos Jogos Escolares e a cessão de bolsas integrais à $15 \%$ dos jovens atletas;

- Construir os Centros de Iniciação ao Esporte, que funcionem de forma integrada às escolas;

- Combinar o esporte de elite ao Ensino Superior, também com bolsas aos atletas (sugestão 15\%); e

- Criar a cultura do esporte vinculado à educação.

\section{Pontos fortes e limitações do estudo}

Um ponto forte do estudo é que, até onde se sabe, este foi o primeiro estudo a examinar a efetividade dos programas em política para o esporte de alto rendimento no Brasil. Os achados são novos e contribuem para explicar a ausência de desempenho do país, no cenário internacional, do esporte de alto rendimento.

Uma das limitações do estudo está em que não foram levantadas aqui proeminências na execução das políticas de países de sucesso, o que poderia contribuir para elucidar detalhes estratégicos/administrativos para a implementação de ações na prática. Ressaltase, entretanto, que tal lacuna não prejudicou a elaboração das ações ora propostas.

\section{Conclusão}

O objetivo do presente estudo foi analisar criticamente a situação atual da política nacional voltada para a descoberta de talentos esportivos e examinar as práticas de países com políticas que têm obtido êxito no esporte para desenvolver uma proposta para o Brasil.

O exame da política para detecção de talentos esportivos, no Brasil, não tem se mostrado eficiente para que seja alcançado o objetivo proposto de figurar entre os dez primeiros países no ranking de medalhas dos Jogos Olímpicos.
A baixa taxa de atletas oriundos de programas esportivos para DTE (7,32\%), dentre as 21 equipes avaliadas, torna-se evidente a ausência de eficácia dos programas. Dentre os programas identificados, alguns têm obtido sucesso, porém, são pontuais, em determinadas cidades e não são governamentais. Nesse contexto, considerando os tamanhos do território e da população brasileiros, foram propostas ações, segundo as quais, acredita-se que o Brasil poderá desenvolver o sistema esportivo nacional, por meio de uma política nacional de DTE, envolvendo organizações públicas e privadas, a fim de superar as dificuldades encontradas no passado. O objetivo de obter o sucesso no desempenho esportivo de alto rendimento se dará ao longo de um processo que promove, ainda, a saúde e a educação na população brasileira.

\section{Declaração de conflito de interesses}

Não há nenhum conflito de interesses em relação ao presente estudo.

\section{Declaração de financiamento}

Financiamento próprio.

\section{Referências}

1. Bastos F da C, Bohme MTS. Comparação Internacional das Politicas Para o Esporte de Alto Rendimento (spliss) - Análise Descritiva dos Resultados Brasileiros. [Online] Universidade de São Paulo (USP), 2010 [Accessed: 30th August 2018] p. 46. Available from: http://cev.org.br/arquivo/biblioteca/compar acao-internacional-das-politicas-para-oesporte-alto-rendimento-spliss-analisedescritiva-dos-resultados-brasileiros.pdf [Accessed: 30th August 2018]

2. Bohme MTS. O tema talento esportivo na ciência do esporte. Revista Brasileira de Ciência e Movimento. 2008;15(1): 119126.

3. Bohme MTS. Athletic Talents II: determination of athletic talents. Revista Paulista de Educação Física. [Online] 1995;9(2): 138-146. Available from: doi:10.11606/issn.25945904.rpef.1995.139478 
4. Bosscher VD, Shibil S, Westerbeek H, Bottenburg M van. Successful Elite Sport Policies: An international comparison of the Sports Policy Factors Leading to International Sporting Success (SPLISS 2.0) in 15 nations. [Online] London, UK: Meyer \& Meyer Verlag; 2015. 404 p.

5. IBGE: Instituto Brasileiro de Geografia e Estatística. Estimativas de população para $1^{o}$ de julho de 2015. [Online] Available from:

https://ww2.ibge.gov.br/home/estatistica/p opulacao/estimativa2015/estimativa_tcu.sh tm [Accessed: 30th August 2018]

6. COB - Comitê Olímpico Brasileiro. Medalhas. [Online] Available from: https://www.cob.org.br/pt/BuscaAvancada/ medalhas [Accessed: 30th August 2018]

7. Câmara dos Deputados. Comissão do Esporte aprova Indicação do Plano Nacional do Desporto. [Online] Portal da Câmara dos Deputados. Available from: http://www2.camara.leg.br/atividadelegislativa/comissoes/comissoespermanentes/cespo/noticias/texto-daproposta-do-plano-nacional-do-desporto [Accessed: 30th August 2018]

8. Silverman JRT $\mid$ JKN $\mid$ SJ. Métodos de pesquisa em atividade física. Porto Alegre, RS: Artmed Editora; 2009. 462 p.

9. Vieira S. Como elaborar questionários. São Paulo, SP: Atlas; 2009. 159 p.

10. Rummel JF. Introdução aos procedimentos de pesquisa em educacao. São Paulo, SP: Globo; 1981. 353 p.

11. Burman E, Parker I. Discourse Analytic Research: Repertoires and readings of texts in action. New York, NY: Routledge; 2016. $188 \mathrm{p}$.

12. Burman E, Parker I. Discourse Analytic Research: Repertoires and readings of texts in action. New York, NY: Routledge; 2016. $188 \mathrm{p}$.

12. Ministério do Esporte. Plano Brasil Medalhas. [Online] Rede do Esporte. Available from: http://www.brasil2016.gov.br/pt- br/incentivo-ao-esporte/plano-brasilmedalhas [Accessed: 9th October 2018]

13. Ministério do Esporte. Rede Nacional de Treinamento. [Online] Available from: http://www.esporte.gov.br/index.php/instit ucional/alto-rendimento/rede-nacional-detreinamento [Accessed: 9th October 2018]

14. Ministério do Esporte. Centros de Iniciação Esportiva. [Online] Available from:

http://www.esporte.gov.br/index.php/cie [Accessed: 9th October 2018]

15. Ministério do Esporte. Centros Olímpicos de Treinamento. [Online] Available from: http://www.esporte.gov.br/index.php/5742 4-inicio-3 [Accessed: 9th October 2018]

16. Ministério do Esporte. Segundo Tempo. [Online] Available from: http://portal.esporte.gov.br/snee/segundote mpo/ [Accessed: 9th October 2018]

17. Ministério da Educação. Atleta na Escola - Programa de Formação Esportiva Escolar. [Online] Available from: http://www.atletanaescola.mec.gov.br/ [Accessed: 9th October 2018]

18. Ministério da Educação. Segundo Tempo/Mais Educação. [Online] Rede do Esporte. Available from: http://www.brasil2016.gov.br/ptbr/megaeventos/paraolimpiadas/investimen tos/segundo-tempo/mais-educacao [Accessed: 9th October 2018]

19. Ministério do Esporte. Futebol feminino. [Online] Available from: http://www.esporte.gov.br/index.php/instit ucional/futebol-e-direitos-dotorcedor/futebol-feminino [Accessed: 9th October 2018]

20. Ministério do Esporte. Sistema Nacional do Esporte. [Online] Available from: http://www.esporte.gov.br/index.php/siste ma-nacional-do-esporte [Accessed: 9th October 2018]

21. Ministério do Esporte. Legado Esportivo. [Online] Available from: http://www.esporte.gov.br/index.php/instit ucional/legado-esportivo [Accessed: 9th October 2018] 
22. Tubino M. Oque é olimpismo. Brasiliense; 2017. 44 p.

23. Brasil. Ministério do Esporte. Política Nacional do Esporte. [Online] Available from:

http://www.esporte.gov.br/index.php/conta to/83-ministerio-do-esporte/institucional/oministerio/sala-de-imprensa2/21849-

politica-nacional-do-esporte [Accessed:

30th August 2018] 